\title{
Analysis of Sloshing Suppressors in Liquefied Natural Gas Carriers Tanks
}

\author{
Danilo de Almeida Barbosa ${ }^{1^{*}}$, Fabio Pavan Piccoli ${ }^{2}$, Daniel dos Santos Moreira ${ }^{3}$
}

${ }^{1}$ Octopus Dofleini: Environmental Physics/Laboratory of Simulation of Flows with Free Surface, Federal University of Espírito Santo, Vitória, Espirito Santo, Brazil

${ }^{2}$ Laboratory of Simulation of Flows with Free Surface, Federal University of Espírito Santo, Vitória, Espirito Santo, Brazil

${ }^{3}$ Department of Physics, State University of Santa Cruz, Ilhéus, Bahia

E-mail: danilofisico@yahoo.com.br

Received: 11 April 2021; Revised: 19 May 2021; Accepted: 27 May 2021

\begin{abstract}
The sloshing problem has been studied in recent decades, as it causes damage to the container structure, caused by hydrodynamic loads. In our work, we show that it is possible to mitigate the action of the fluid on the structure. First, we applied Smoothed Particle Hydrodynamics (SPH) to perform numerical simulations involving the sloshing effect in tanks used to transport Liquefied Petroleum Gas similar to the physical experiments found in the literature. Then, we added (on the container floor) to our numerical model attenuation devices to reduce the sloshing effect. Two types of sloshing suppressors were used, where two different heights are assigned and tested. In addition, we changed the deflector's morphology, leaving it in the shape of an arrow pointing upwards. The results have shown that the baffles can be efficient mechanisms for the suppression of sloshing and that there is a strong relationship between the height of the baffles and the level of fluid concerning the tank.
\end{abstract}

Keywords: baffles, arrow baffles, sloshing, Smoothed Particle Hydrodynamics

\section{Introduction}

There is a question that has been studied for a long time about sloshing and suppressing its effects: how far are deflectors capable of suppressing the hydrodynamic loads produced by tank oscillations?

Although there have been reports of sloshing since the 19th century [1]-[4], this subject gained more prominence during the aerospace race [5], [6], increasing industrial interest in the subject in recent decades, in which it aims to reduce the harmful effects caused by this phenomenon on boats, aircraft and artificial satellites and also benefit buildings in regions subject to earthquakes. Abramson studied the sloshing and suppression mechanisms, showing fateful examples where spacecraft and satellites had problems during the flight due to it [5]. He also examined the various types of sloshing deflector mechanisms in storage tanks for propellant fuels from satellites or aircraft, looking to find hydrodynamic loads acting on the vehicle structure or the suppression devices after the fluid displacement. For this, cylindrical, spherical, and conical geometries with and without baffles were tested by Abramson. At the time, the effects produced by sloshing had already been known, such as the resonance fatigue and vehicular instability (vessel/ watercraft) caused by hydrodynamic loading and oscillation of the fluid portion mass center.

Copyright (C2021 Danilo de Almeida Barbosa, et al.

DOI: https://doi.org/10.37256/est.222021866

This is an open-access article distributed under a CC BY license

(Creative Commons Attribution 4.0 International License)

https://creativecommons.org/licenses/by/4.0/ 
There are also reports of accidents caused by sloshing in marine vessels [7], where sloshing problem has caused accidents involving ships and fishing boats, such as GAUL fishing boat in February 1974 and Artic Rose fishing boat, which sank on April 2, 2001, giving rise to environmental damage with fuel spillage.

Investigations after respective shipwrecks revealed that the vessels sank rapidly due to the dynamical effect of the free surface of the water associated with the flooding inside the compartments as the liquid starts to move freely [7]. Therefore, studying sloshing requires estimating how the pressure is distributed and how to control the external forces involved. Moreover, this pressure in confined liquids caused by the transfer of the amount of movement from the container to the fluid is proportional to the rate of change in the velocity of the container and the movement of the free surface [8], [9].

Another approach applies to the increasing exploration and exploitation of offshore oil and the consequent increase in the number of Floating Production Storage and Offloading (FPSO) platforms, and vessels to transport this fluid. Under standard conditions of fluid mass transport, the sloshing can produce a negative effect on the structures due to the dynamic loads generated, which can cause serious damages to boats.

Tsukamoto [10] states that to reduce the effect of sloshing in containers, attenuation devices, such as deflector blades positioned on the walls and the ceiling or bottom of the tanks must be installed. Although, according to the author, these mechanisms are effective only at low fill levels. Tsukamoto [10] states that to reduce the effect of sloshing in containers, attenuation devices, such as deflector blades positioned on the walls and the ceiling or bottom of the tanks must be installed. Although, according to the author, these mechanisms are effective only at low fill levels. Considering Tsukmato's conclusion [10], Thirunavukkarasu and Rajagopal [11] conducted a study with a combination of horizontal and vertical baffles that are placed at the variable mass region of the tank was considered for the sloshing analysis. The tank was excited with sinusoidal motion with an excitation amplitude of $20 \mathrm{~mm}$ and frequency depending on the fill level of water in the tank. Therefore, it turns out that it is necessary to develop tanks capable of reducing the harmful effects of sloshing considering the limit of container filling. In addressing this topic, our work was concerned with testing two types of sloshing suppressors: (1) vertical baffles, located in the center of the tank and tested at two different heights; (2) Subsequently, we changed the morphology of the baffles, leaving them in the shape of an arrow pointing upwards.

To assist us in the tests, we used the smoothed particle hydrodynamics SPH methods [11]-[14] and simulated the experimental work of Kishev et al. [15].

\section{Experimental setup}

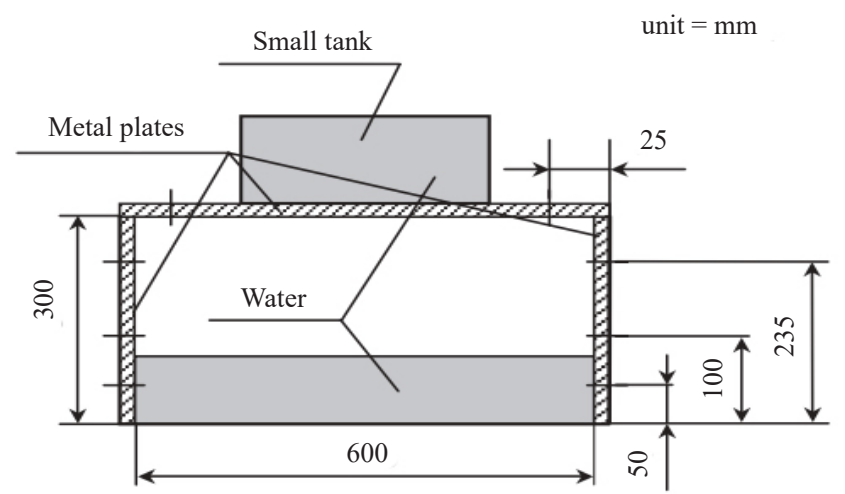

Figure 1. Experimental setup. Schematic view of the tank with dimensions and principal pressure gauge positions indicated. Font: Kishev et al. [15]

The rectangular tank used in the experiments, which is made of Plexiglas, was $60 \mathrm{~cm}$ wide, $30 \mathrm{~cm}$ high, and $10 \mathrm{~cm}$ deep. The tank has no internal structure so that it simulates a smooth tank of the type existing in membrane-type LNG 
carriers. On each sidewall of the tank, several positions were prepared for pressure gauges and there were ten possible positions on each tank wall. However, we use only a gauge of $100 \mathrm{~mm}$ high placed on the left wall in our work. The sidewalls of the tank were fitted with metal (copper) plates to prevent thermal shock on the gauges when passing from air to water. Such a metal plate was added also on the tank roof for the last group of experiments to make it possible to measure pressures on the roof without thermal shock on the gauges. In that case, a small tank filled with water was also added on top. A high-speed video camera was mounted on a frame moving with the tank. A schematic view of the tank is shown in Figure 1. The experimental setup is shown in Figure 2 [15].

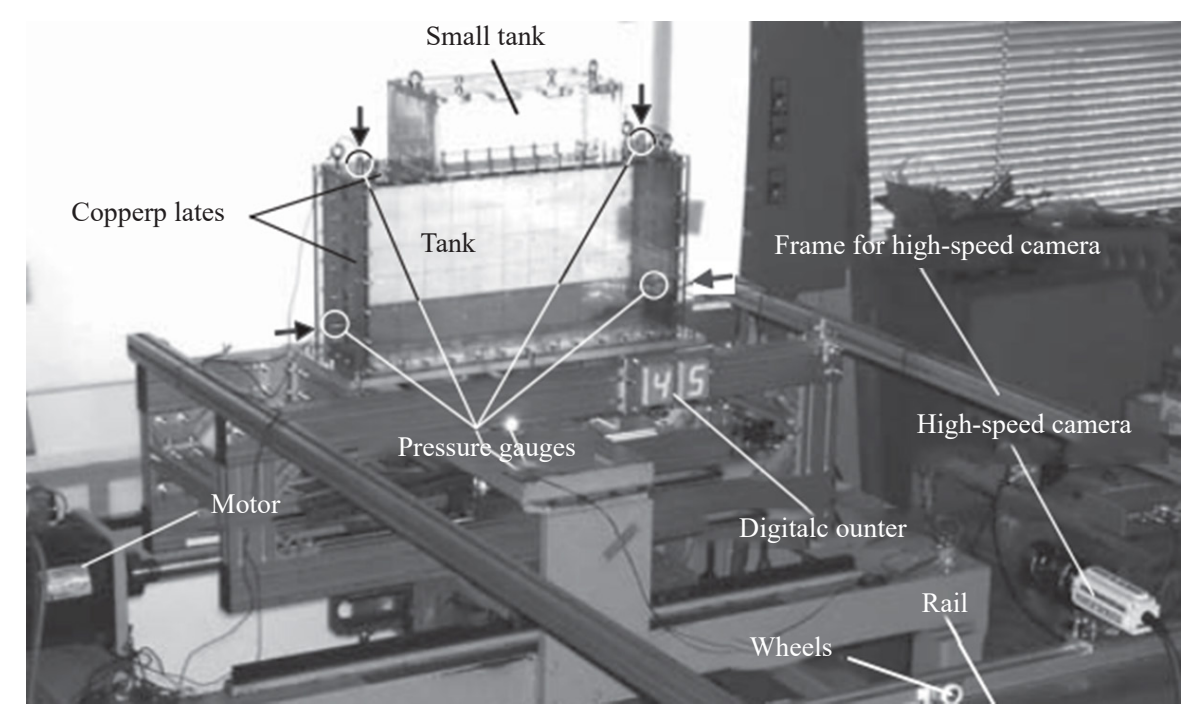

Figure 2. Experimental setup. Arrows show positions of pressure gauges for that particular experimental case

\section{Numerical setup}

Kishev et al. [15] performed numerical experiments based on the Eulerian Constraint Interpolation Profile (CIP) and its variants and compared it against their physical experiments. That experiment consisted of a $60 \times 30 \times 10 \mathrm{~cm}$ tank. We reproduced the kinematic and dynamic appreciation with the SPH-COULOMB, taking advantage of testing different values of beta and alpha of the artificial viscosity. In addition to using the experimental results obtained by Kishev et al. [15] to validate our model, we also compared the results with those found by Gotoh et al. [16] for the same configuration. The tank oscillated in sway with the motion described as shown in Figure 3.

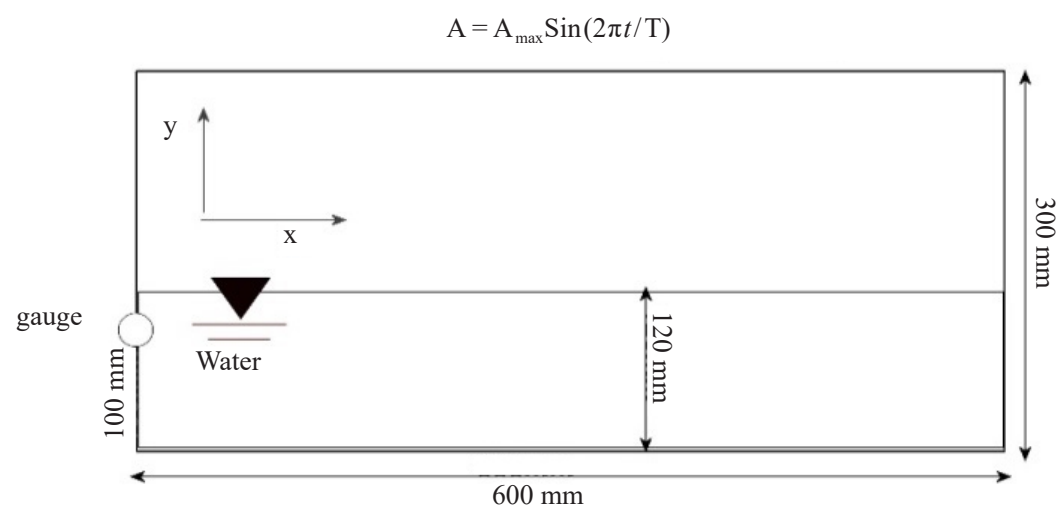

Figure 3. Geometric description of Kishev et al. [15] 
During the experiment, the tank was partially filled with water, around $12 \mathrm{~cm}$ (or $120 \mathrm{~mm}$ ) deep. The maximum range of motion was $5 \mathrm{~cm}$, while the excitation period was $1.3 \mathrm{~s}$. Our simulation consists of several scenarios. Tanks were tested with virtual particles to simulate the contour. The domain particles have a $6 \mathrm{~mm}$ diameter. Figure 4 shows this configuration after the first-time step.
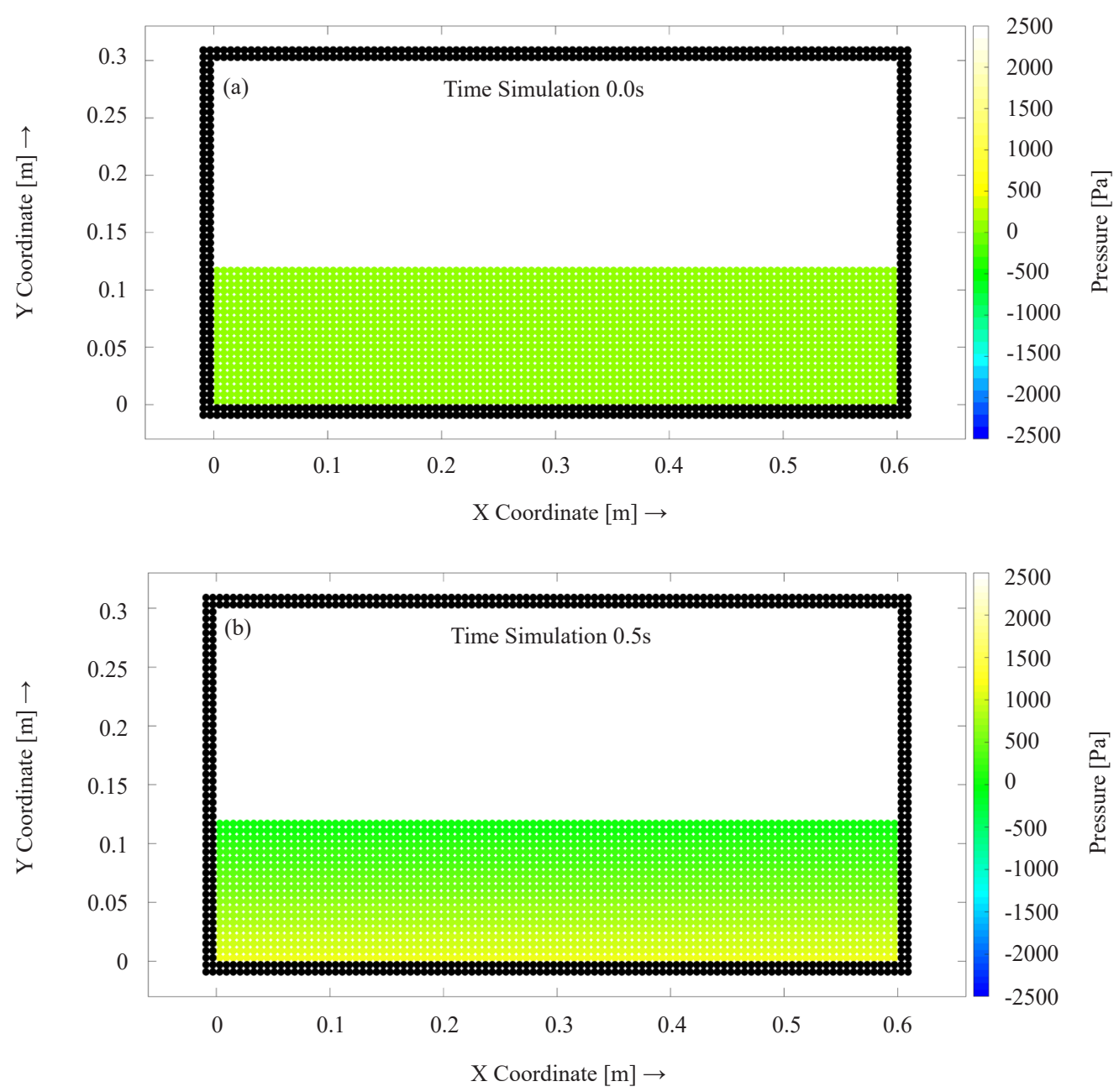

Figure 4. In (a) Configuration at the time simulation 0.0 seconds and pressure null.

In (b) same setting for 0.05 seconds of simulation and a maximum pressure of $1180.00 \mathrm{~N} / \mathrm{m}^{2}(\mathrm{~Pa})$, both with the null beta factor

\section{Mathematical modelling}

The mathematical formulation applied to the sloshing problem is, as part of the natural phenomena, based on the fundamentals of the conservation laws of classical mechanics. Fortunately, the laws governing hydrodynamic phenomena can be expressed in mathematical equations, which, in general, are partial differential equations. In this case, the equations governing the phenomenon are the conservation of mass (Equation (1)) and conservation of momentum (Equation (2)).

Conservation of mass equations:

$$
\frac{D \rho}{D t}=-\rho \frac{\partial u_{i}}{\partial x_{i}}
$$


where $\rho$ is the density, $u_{i}$ is the velocity, $t$ is the time, and $x_{i}$ is the coordinate in the Cartesian plane or in threedimensional $i=1,2,3$.

Conservation of Momentum:

$$
\frac{D u_{i}}{D t}=-\frac{1}{\rho} \frac{\partial P}{\partial x_{i}}+\frac{1}{\rho} \frac{\partial \tau_{i j}}{\partial x_{j}}+g_{i}
$$

where

$$
\tau_{i j}=\mu\left(\frac{\partial u_{i}}{\partial x_{j}}+\frac{\partial u_{j}}{\partial x_{i}}\right)-\frac{2 \mu}{3} \frac{\partial u_{m}}{\partial x_{m}} \delta_{i j}
$$

where $P$ is the pressure, $\mu$ is the kinematic viscosity, and $g_{i}$ is theexternal force. The second term of Equation (2) is the surface force due to pressure per unit mass, and the third term is the force due to surface shear stress (or due to viscosity) per unit mass.

\subsection{State equation of artificial compressibility}

In the SPH method, an artificial compressibility technique is used to model the incompressible flow as a slightly compressible flow. According to Liu \& Liu [14], there are two ways to impose the incompressibility: by Equation (4), which is applied for those cases involving low Reynolds Numbers incompressible flows using SPH; and by Equation (5), Tait equation, which is also used to model free surface flows.

$$
\begin{gathered}
P=c^{2} \rho \\
P=\beta\left[\left(\frac{\rho}{\rho_{0}}\right)^{\gamma}-1\right]
\end{gathered}
$$

Where $\beta=c^{2} \rho_{0} / \gamma$ and $\gamma$ is a constant (equal 7 in most circumstances), $\rho_{0}$ is the reference density, and $c$ is the speed of sound in water. $\beta$ is a problem-dependent parameter that sets a limit for the maximum change of the density. In most circumstances, $\beta$ can be taken as the initial pressure [13].

\subsection{Boundary treatment}

Most Smoothed Particle Hydrodynamics (SPH) models usually treat the domain boundary with the use of virtual particles (or ghost particles). These particles are "placed" on the domain limits. Thus, a repulsive force is attributed to them to avoid interpenetration. Classically, the repulsive force used is derived from the Lennard-Jones' (LJ) potential, widely employed in molecular dynamics [12]-[15].

An alternative to the $\mathrm{LJ}$ force presented in this paper is the Coulomb force $\left(F^{\text {Coulomb }}\right)$ [17], [18], Equation 6, which, like the classical LJ technique, has the sole and exclusive purpose of keeping the particles inside the domain delimited by the virtual particles. Like the previous case, the polarization (or neutralization) has the same nature as the virtual particles, i.e., virtual and numerical, and therefore it does not allow physical discussion. 


$$
F_{i}^{\text {Coulomb }}= \begin{cases}k \frac{\left|Q^{a}\right|\left|Q^{b}\right|}{\left(x^{2}+y^{2}+z^{2}\right)^{3 / 2}}\left(x^{2} e_{i}+y^{2} e_{j}+z^{2} e_{k}\right) & , r^{a b} \leq r_{o} \\ 0 & , r^{a b}>r_{o}\end{cases}
$$

where $\hat{r}_{i}=\frac{r_{i}}{\left|r_{i}\right|}$ and $\left|r_{i}\right|=r$ and $r^{a b}=\left\|x_{a}^{i}-x_{b}^{i}\right\|$ and $r_{o}$ is the cutoff.

\section{Results}

\subsection{Qualitative pressure}

Four types of tests were performed: (1) tank without baffles; (2) tank with the 0.05 meters defector; (3) tank with a strap of 0.1 meters; and (4) tank with a screen in the shape of an arrow. Figure 5 compares the first three scenarios. The negative scale was purposely used to verify the non-physical fluctuations of pressure. At the top, the maximum pressure obtained exceeds $4000 \mathrm{~Pa}$. It is possible to observe that the action of the baffles with 0.1 meters reduces the total hydrodynamic load. Unlike the 0.05 meters, baffles proved to be inefficient.

In Figures 5, 6, and 7, and yet Table 1 is possible to notice that 0.05 meters $(50 \mathrm{~mm})$ barrier proved to be inefficient. The baffles with 0.1 meters $(100 \mathrm{~mm})$ showed a greater attenuation of the hydrodynamic load on the walls. During the fluid-structure interaction, more precisely during the run-up in $2.3 \mathrm{~s}$, the total pressure without the deflectors reached $4728 \mathrm{~Pa}$. With the addition of the $0.1 \mathrm{~m}$ deflectors, the reduction of the total hydrodynamic load was significant and equal 3612.15 Pa. Figure 7 shows the same configuration as Figure 6, however, for different instants of time when a pressure underestimation is highlighted, incapable of generating damage to the problem. Another configuration was tested with a change in the morphology of the arrow-shaped baffles (Figure 9).

Table 1. Pressure dates to Figures setup 5 and 6 and 7

\begin{tabular}{cccc}
\hline $\begin{array}{c}\text { Setup baffles } \\
\text { height }(\mathrm{m})\end{array}$ & $\begin{array}{c}\text { Figure 5 Max } \\
\text { Pressure }(\mathrm{Pa})\end{array}$ & $\begin{array}{c}\text { Figure 6 Max } \\
\text { Pressure }(\mathrm{Pa})\end{array}$ & $\begin{array}{c}\text { Figure 7 Max } \\
\text { Pressure }(\mathrm{Pa})\end{array}$ \\
\hline Without baffles & 4251.78 & 4728.84 & 3943.30 \\
Vertical $0.05 \mathrm{~m}$ & 4666.96 & 3926.30 & 4622.69 \\
Vertical $0.1 \mathrm{~m}$ & 3638.77 & 3612.15 & 3787.18 \\
\hline
\end{tabular}

For the same instant of time, the arrow-shaped baffles (Figure 9) proved to be more efficient for sloshing suppression when compared to all other scenarios. In the region of the baffles, the hydrodynamic load is greater, reducing the effect of the pressure on the tank walls. Bar Figure 8 compares the voltages in the left wall captured by the gauge for the three types of baffles.

The vertical baffles were compared with the arrow-shaped baffles (Figure 9). At the same time, the baffles arrow was more efficient for sloshing suppression when compared to all other scenarios as shown by Table 2 and Figure 11. In the baffles region, the hydrodynamic load is higher, reducing the effect of pressure on the tank walls. Note in Figure 7 that the hydrodynamic pressure value in 2.3 s exceeds $8400 \mathrm{~Pa}$ in a tank without the baffles and greater than $38000 \mathrm{~Pa}$ with 0.1-meter vertical baffles as shown in Figure 9. 

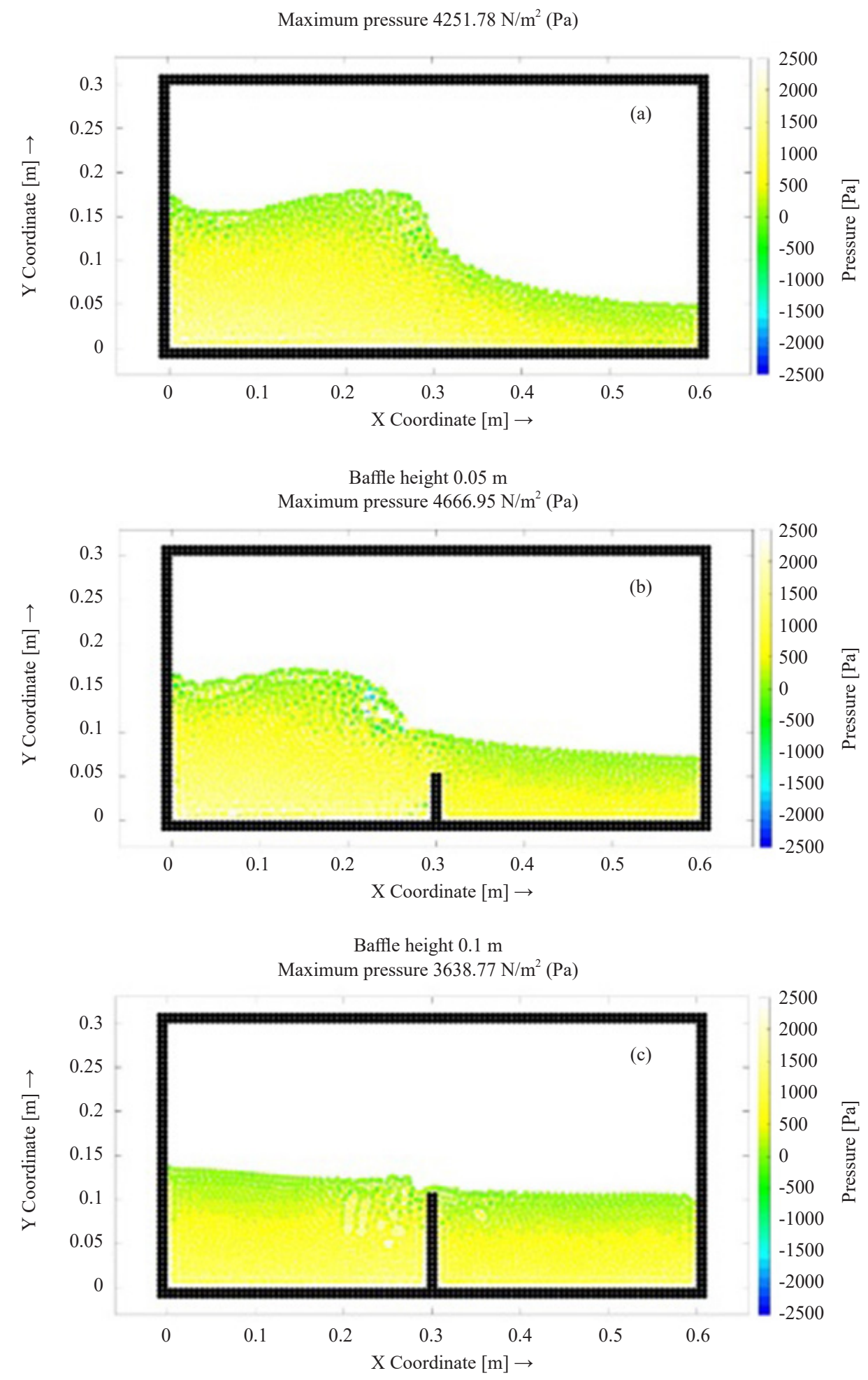

Figure 5. Snapshots in $2.0 \mathrm{~s}$ of simulation time: (a) no baffles, (b) baffles of 0.05 meters $(50 \mathrm{~mm})$ high, and $(\mathrm{c})$ the same configuration with baffles of 0.1 meter $(100 \mathrm{~mm})$ 

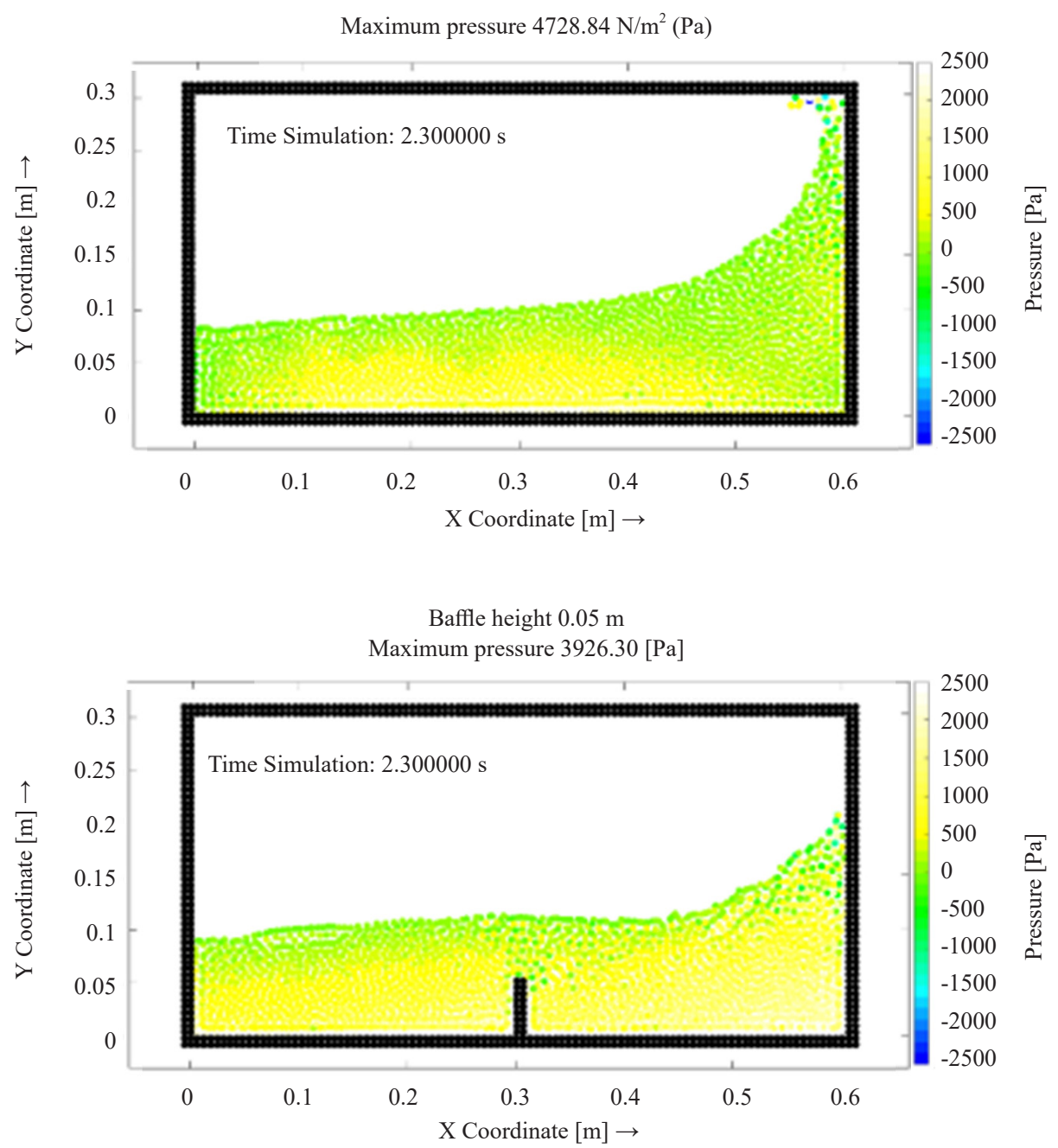

Baffle height $0.1 \mathrm{~m}$

Maximum pressure $3612.15[\mathrm{~Pa}]$

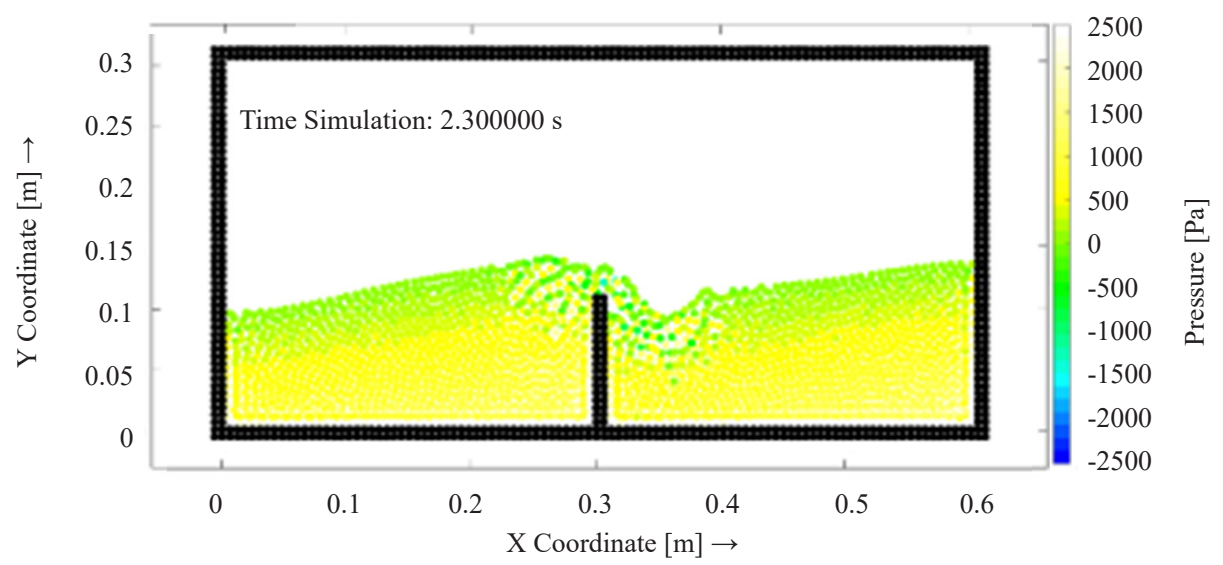

Figure 6. Occurrence of the run-up in the same configuration of Figure 5 

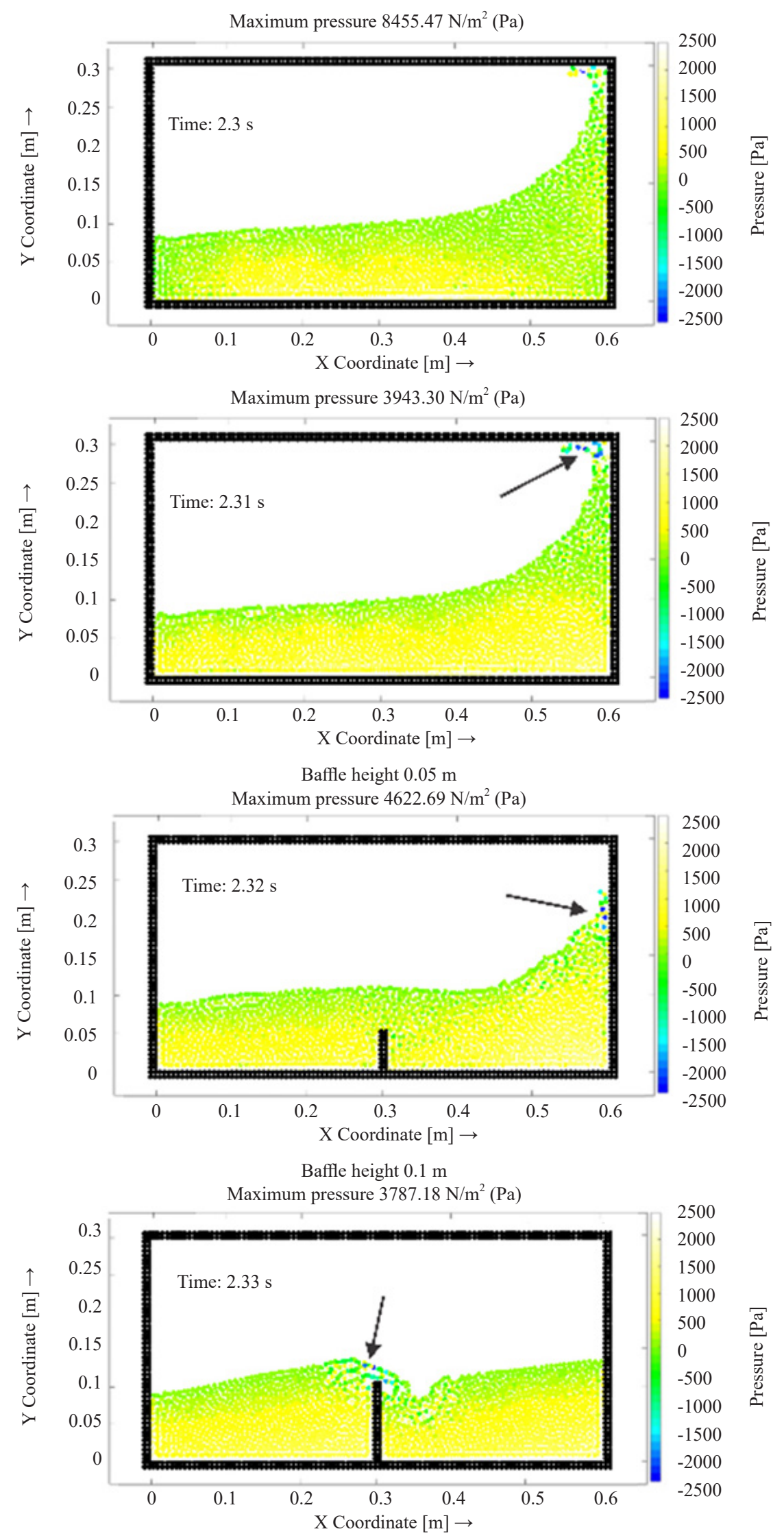

Figure 7. Snapshots for the same configuration of Figures 5 and 6 , showing (highlighted) small non-physical fluctuations of pressure 
Relationship of Hydrodynamic Load to Baffles Size

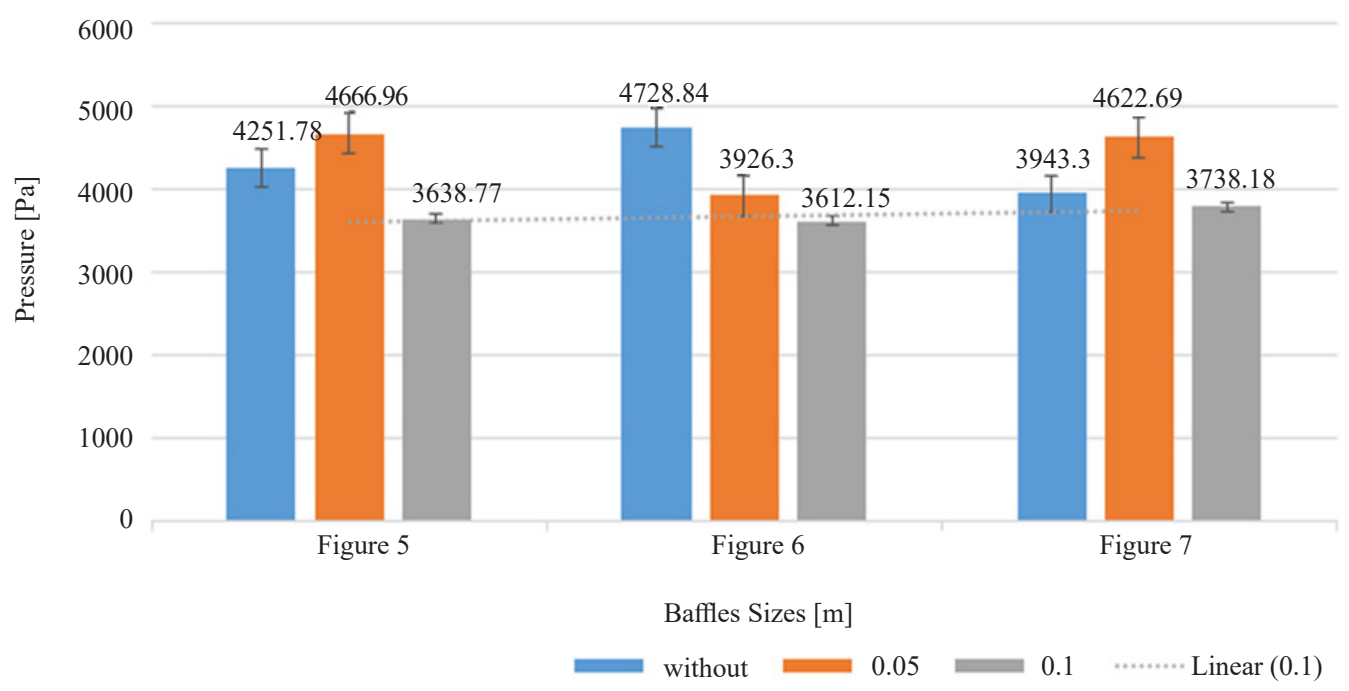

Figure 8. Comparison between the hydrodynamic loads captured by the gauge positioned at coordinates $\mathrm{Y}=0.0 \mathrm{~m}$ and $\mathrm{X}=0.1 \mathrm{~m}$ for three types of internal tank structures was shown in Figure 3

Table 2. Comparison between vertical baffles and arrow-shaped baffles

\begin{tabular}{cccc}
\hline Baffles Shape & $\begin{array}{c}\text { Max pressure }(\mathrm{Pa}) \\
\text { in 2.3 s }\end{array}$ & $\begin{array}{c}\text { Max pressure (Pa) } \\
\text { in 2.9 s (Figure 10) }\end{array}$ & $\begin{array}{c}\text { Max pressure }(\mathrm{Pa}) \\
\text { in 3.0 s }\end{array}$ \\
\hline Without baffles & 4728.84 & 9286.65 & 3641.80 \\
Vertical 0.1 m & 3612.15 & 3626.66 & 3769.36 \\
Arrow 0.1 m & 3427.90 & 3390.31 & 3722.42 \\
\hline
\end{tabular}

Maximum pressure without baffle $5006.41 \mathrm{~N} / \mathrm{m}^{2}(\mathrm{~Pa})$ in $2.30 \mathrm{~s}$ of time simulation

Baffle height $0.1 \mathrm{~m}$

Maximum pressure $3808.88 \mathrm{~N} / \mathrm{m}^{2}(\mathrm{~Pa})$

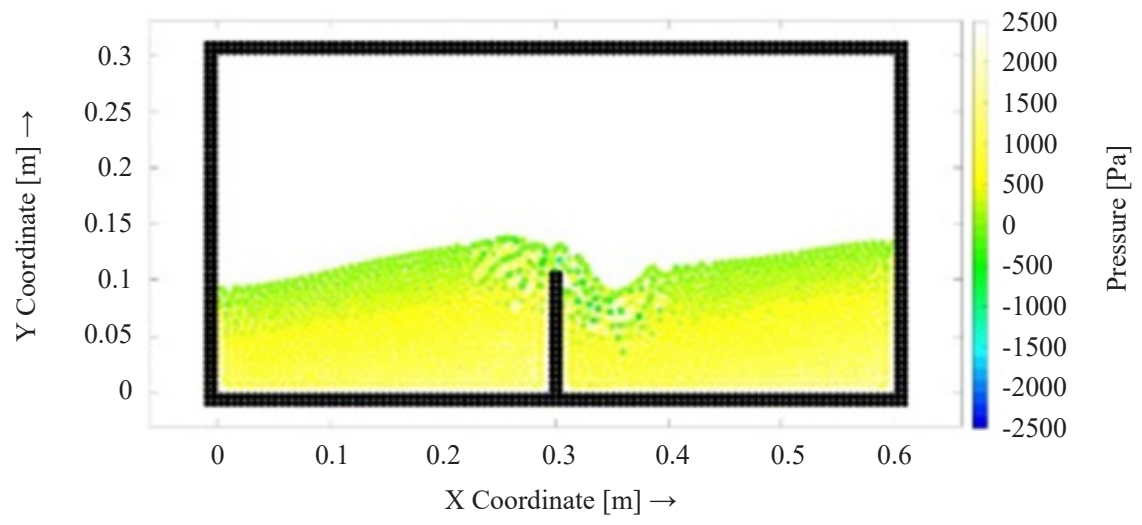




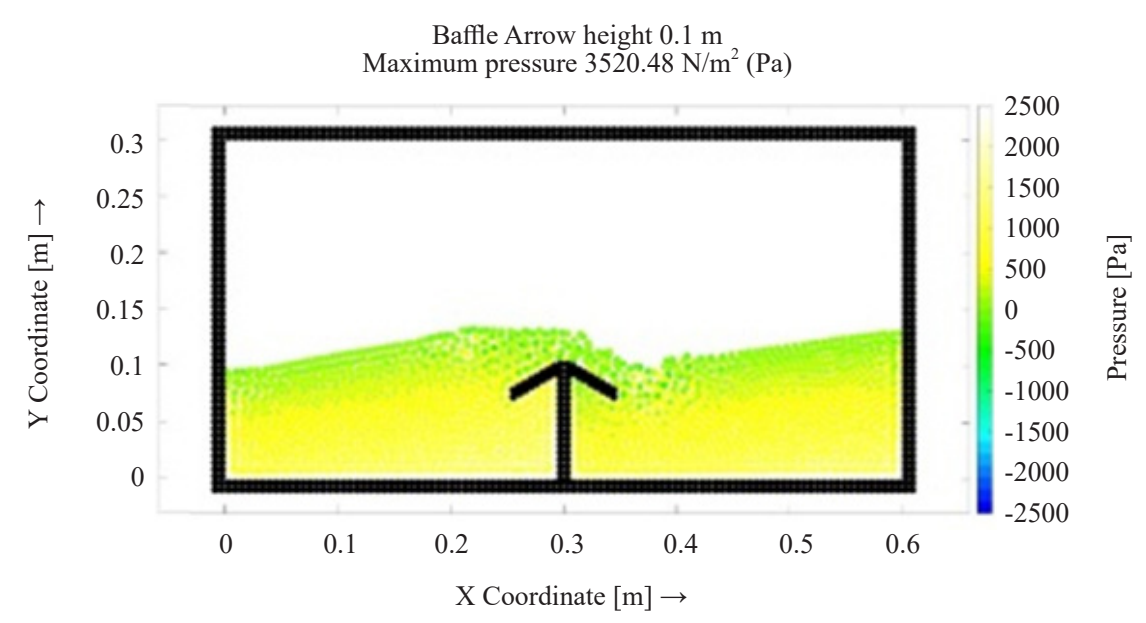

Maximum pressure without baffle $4945.65 \mathrm{~N} / \mathrm{m}^{2}(\mathrm{~Pa})$ in $3.00 \mathrm{~s}$ of time simulation
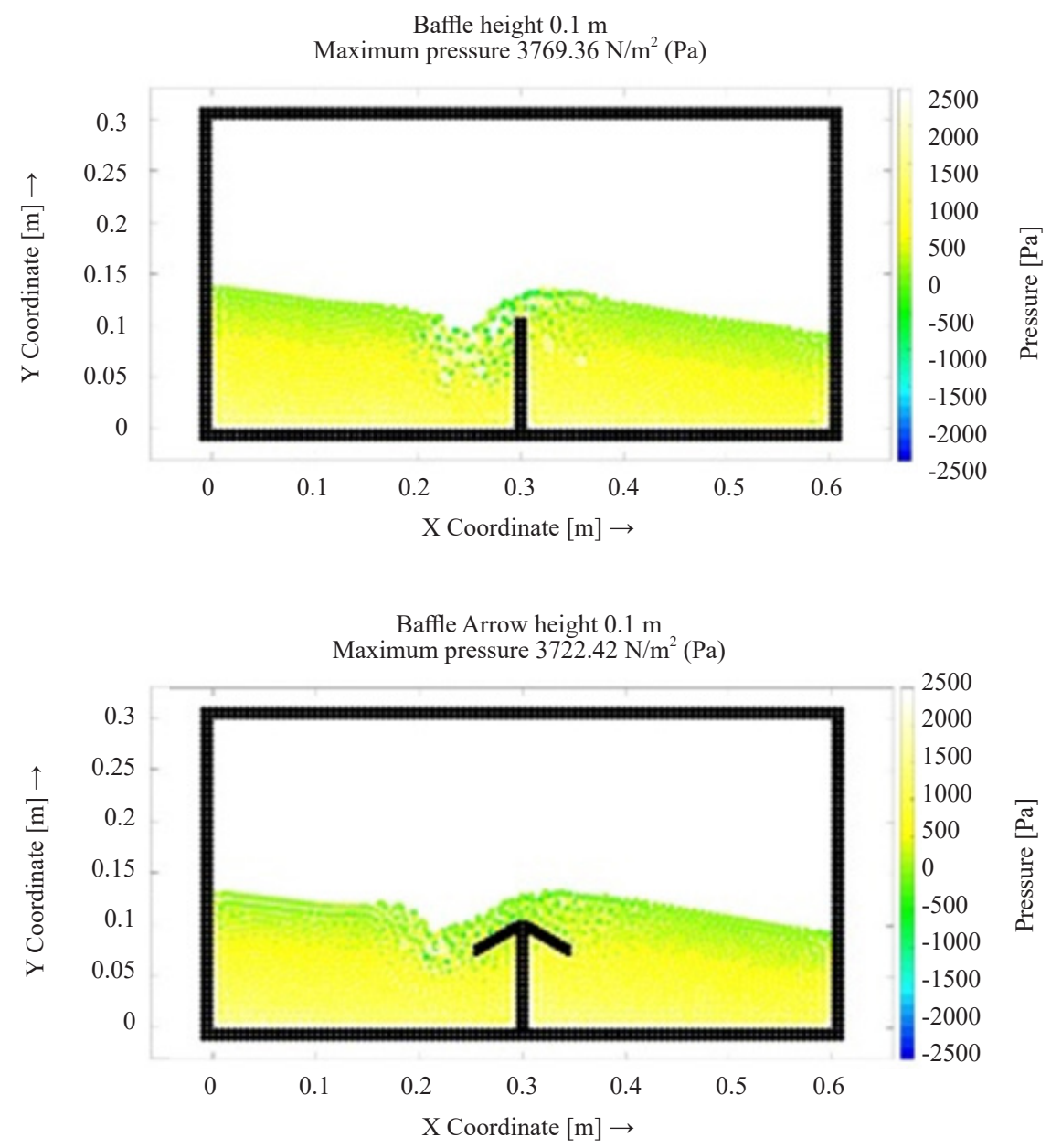

Figure 9. Comparison of the flow pressure field with baffles in different morphologies 

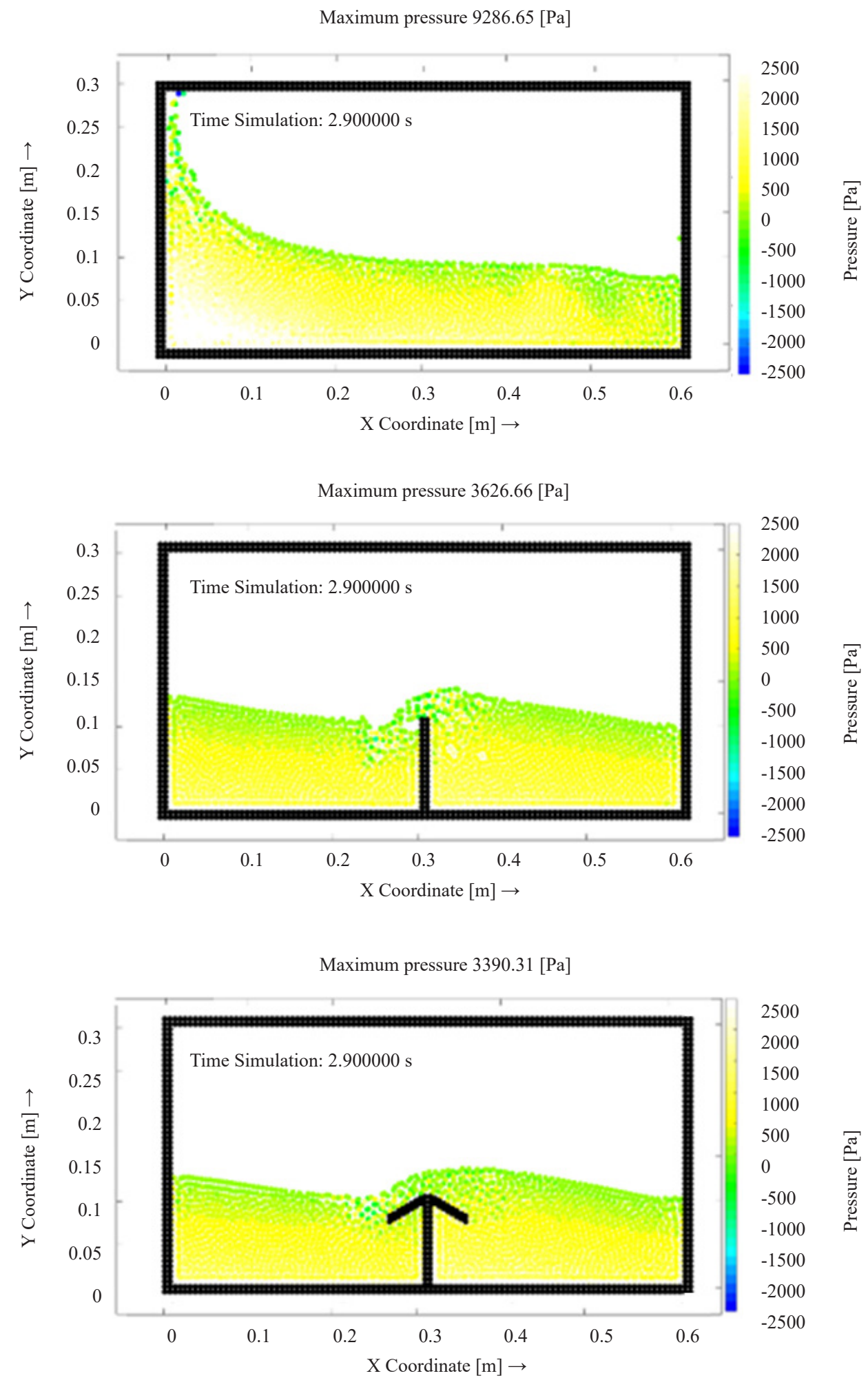

Figure 10. Instant $2.9 \mathrm{~s}$. The moment when the most intense hydrodynamic load was captured 
Max Pressure $\times$ Instante of Time $\times$ Baffle Type

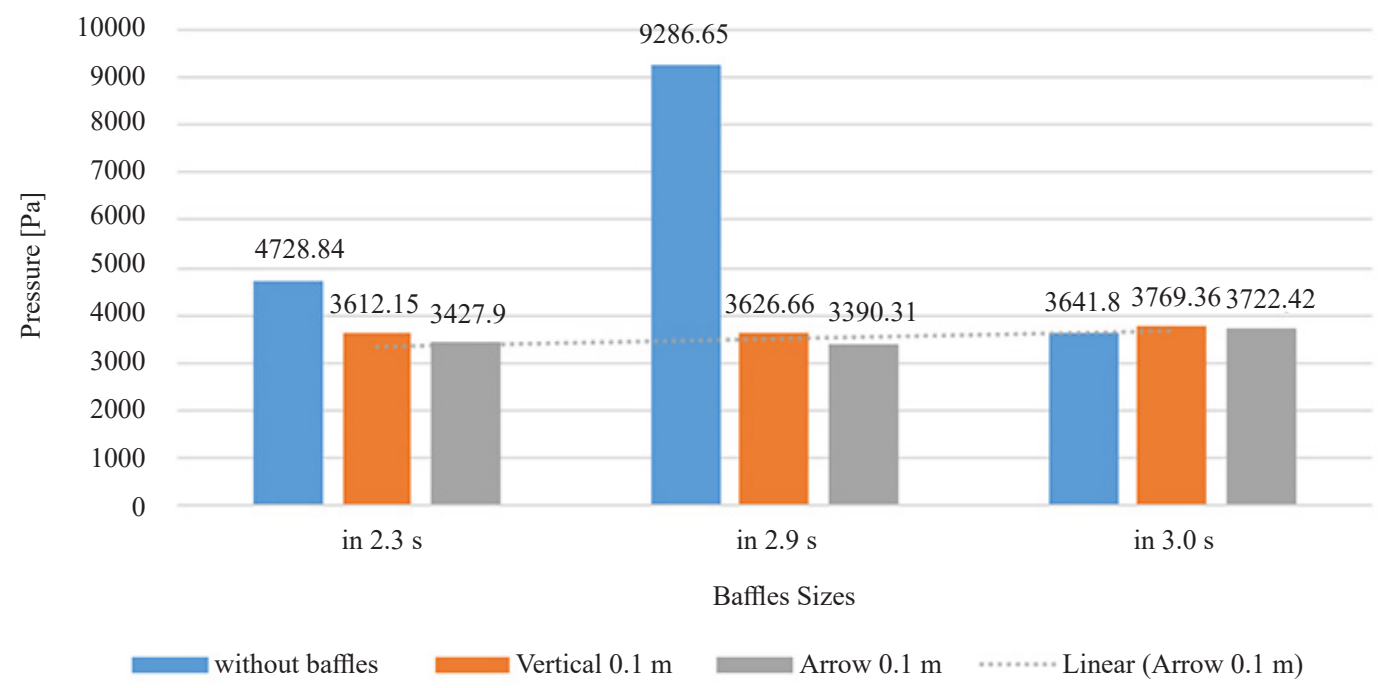

Figure 11. Behavior of hydrodynamic pressure for three distinct morphologies at the time of $2.3 \mathrm{~s}, 2.9 \mathrm{~s}$ and $3.0 \mathrm{~s}$

\subsection{Pressure quantification}

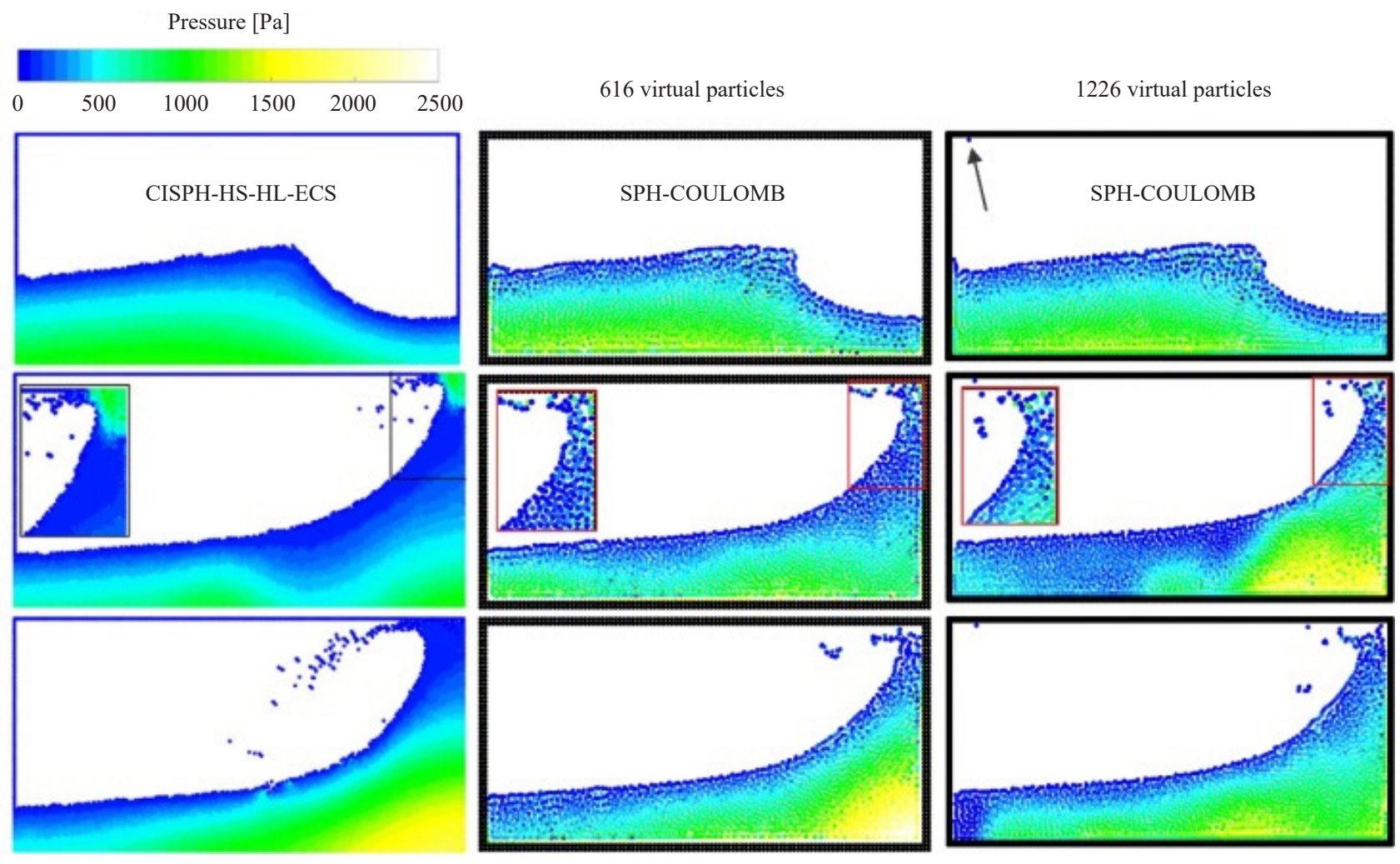

Figure 12. In the center, the flow with 1226 boundary particles and to the right of the center 616 virtual particles. Left of center, modified SPH (ISPH) tested by Gotoh et al. [16].

Rectangular Highlight refers to a small "underestimation" of pressure, which was also found by us 
Before quantifying the pressure, a qualitative comparison with the results obtained by Gotoh et al. [16] was performed. To simulate the physical configuration, those authors considered particles with a diameter of $3 \mathrm{~mm}$-about 8000 particles. While in this work, the diameter was $6 \mathrm{~mm}$, corresponding to 2000 domain particles. They tested two different techniques and a slight underestimation of pressure is highlighted in Figure 12.

To reduce the computational cost, one of the top layers of the tank was removed, which justifies a small viscous diffusion (pointed by an arrow), however, despicable.

Figure 13 compares the numerical experiments with the physical experiment by Kishev et al. [15]. For more information on method modifications, see Gotoh et al. [16].

Despite the morphological aspect of the configuration where the 1226 virtual particle boundary treatment is closer to the actual flow profile, the use of 616 ghost particles showed better approximations under the estimate for the flow dynamics values. Figures 14 and 15, for example, draw a quantitative parallel between the pressures encountered during the experiment by Kishev et al. [15] with the numerical technique used by him and with the one used and modified in this work.

Figure 16 shows the Pressure versus Time for three different scenarios. In all scenarios, the pressure profile was recorded at the position $(x, y)=(0.0,0.1)$ of the container. The upper graph represents the pressure in the scenario without baffles, the middle graph consists of the scenario with straight baffles located in the center of the tank and the lower graph is the scenario with an arrow-shaped deflector in the center of the tank. Thus, it is possible to observe that the baffles are efficient in terms of load/pressure reduction on the walls of the container, especially the baffles in the shape of an arrow.

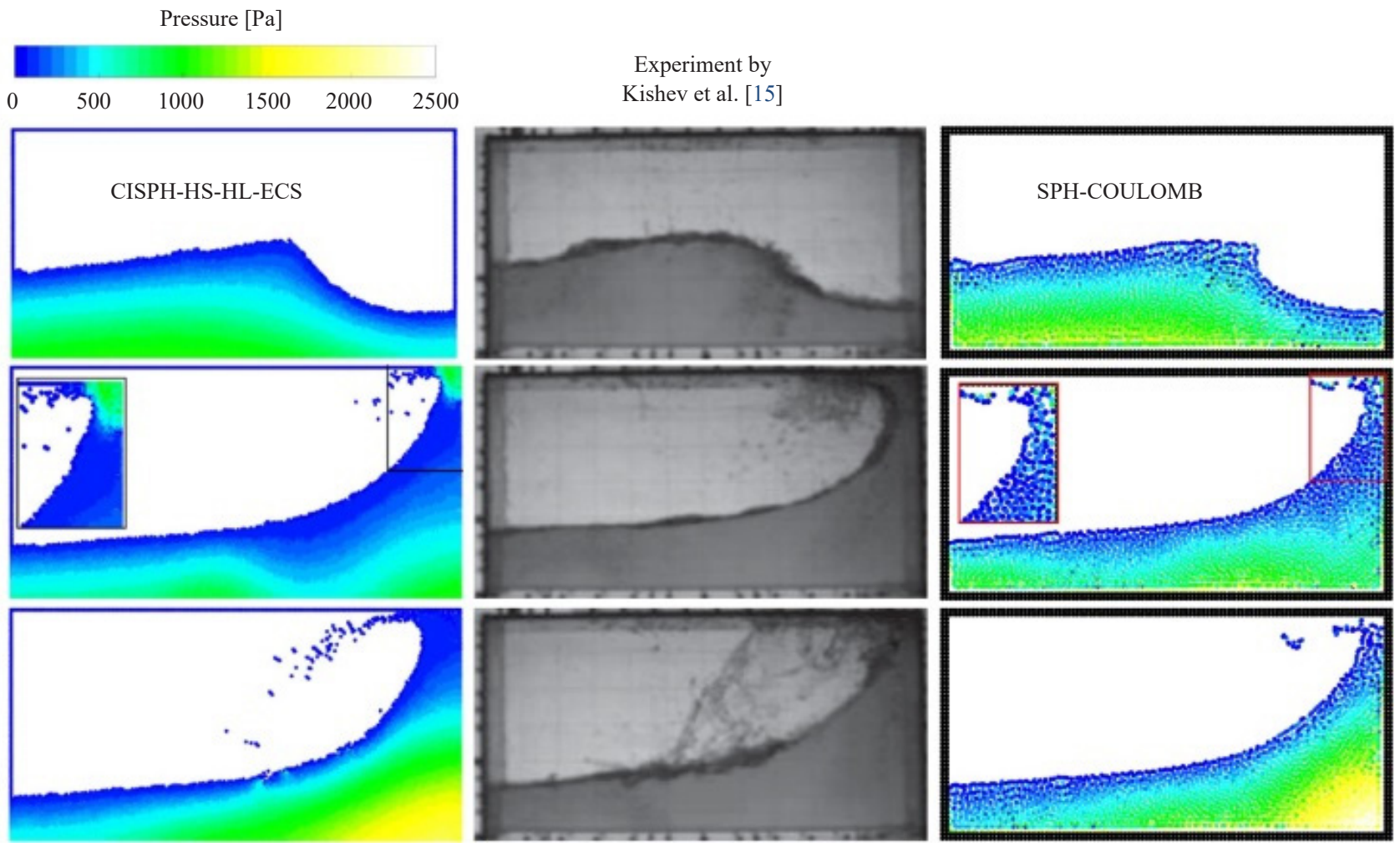

Figure 13. Left center plots, flow profile described by Gotoh et al. [16]. At the center plots the experiment of Kishev et al. [15]. To the right, our contribution. The quantitative relation is performed in Figure 12 

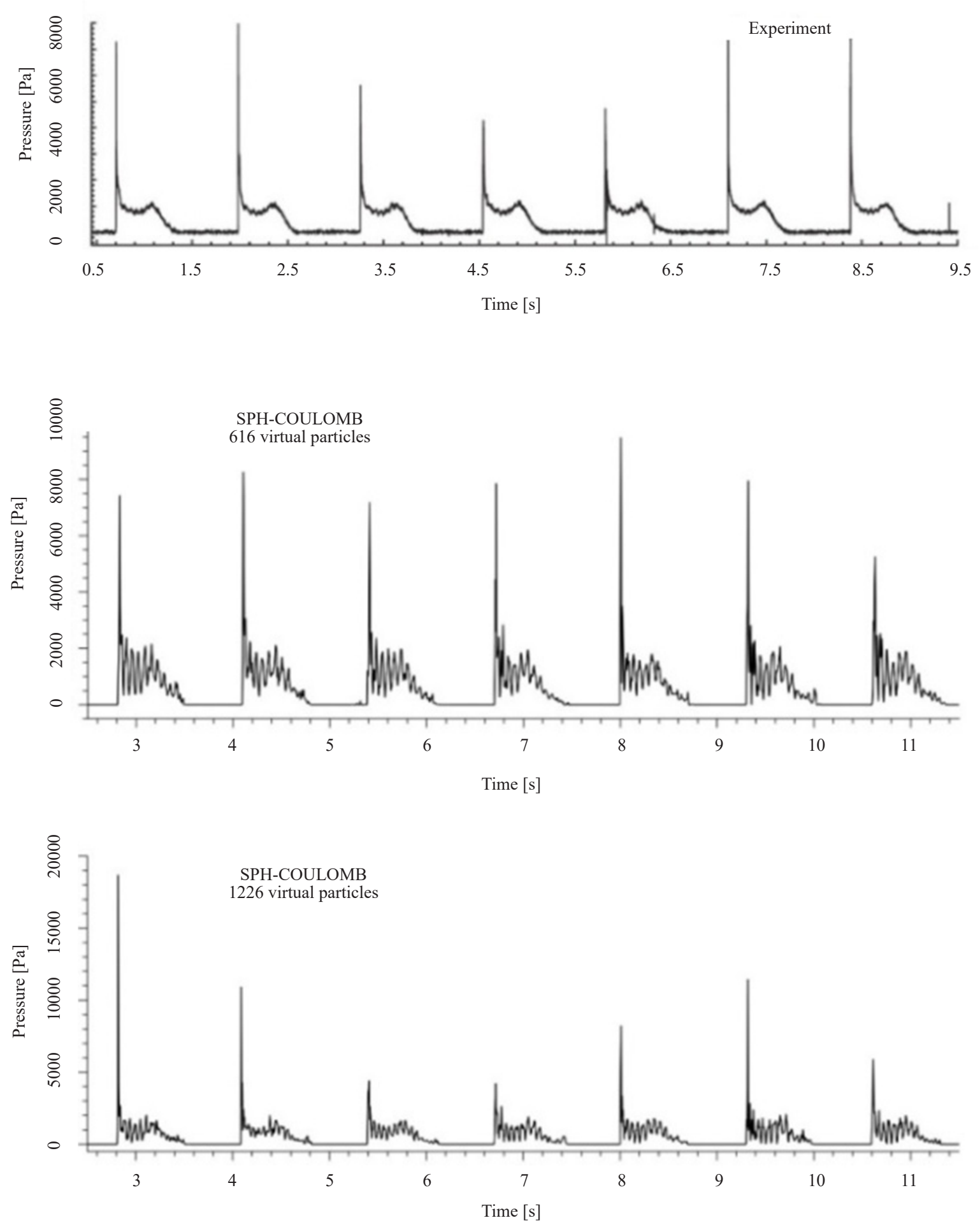

Figure 14. At the top, it corresponds to the values collected from the physical experiment by Kishev et al. [15]. Below in the center, SPH with 616 virtual particles. The third Figure (top to bottom), SPH with 1226 virtual particles 

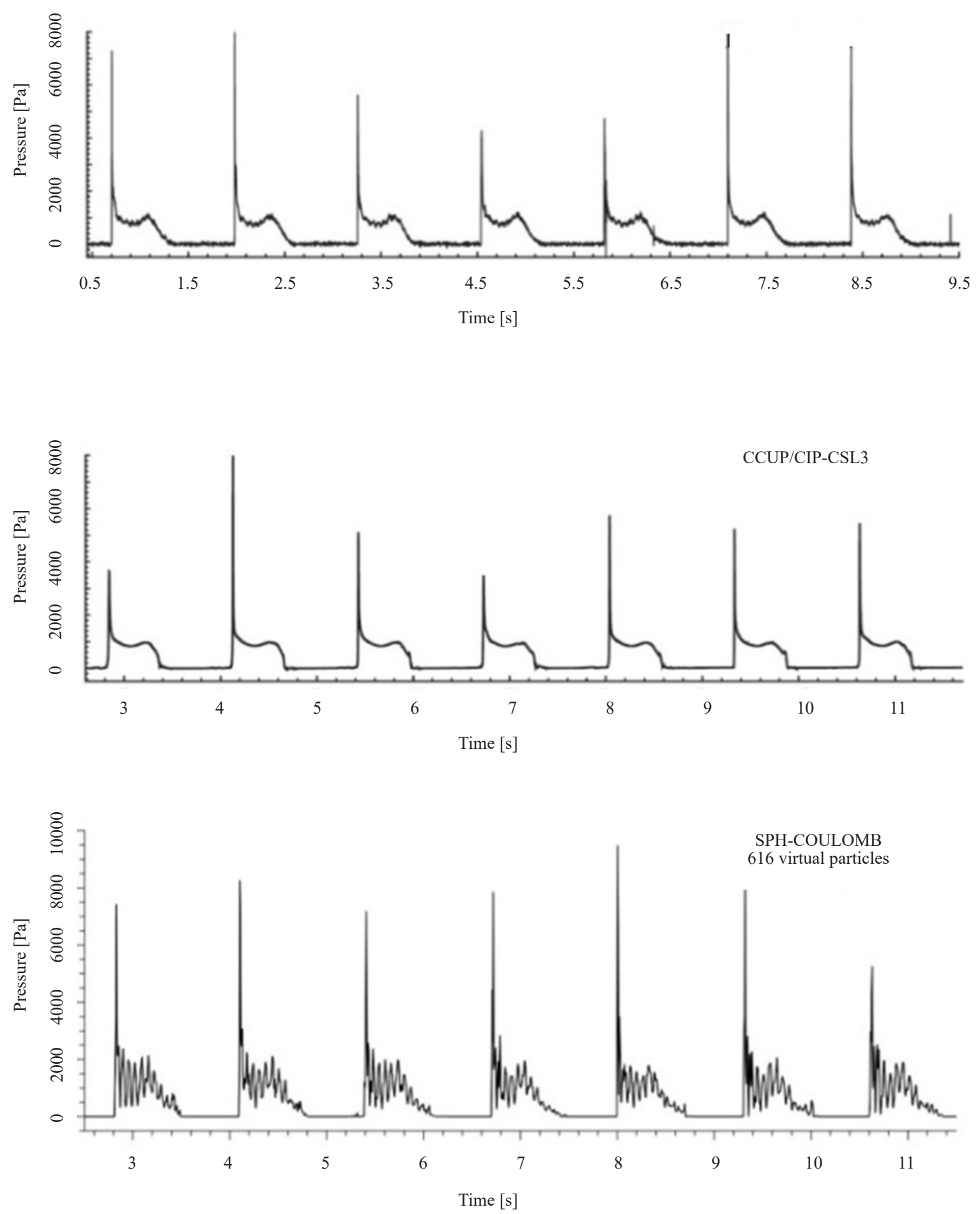

Figure 15. The parallel between physical experiments and numerical experiments for pressure data. Regarding the model applied to the SPH method, 616 virtual particles were used 

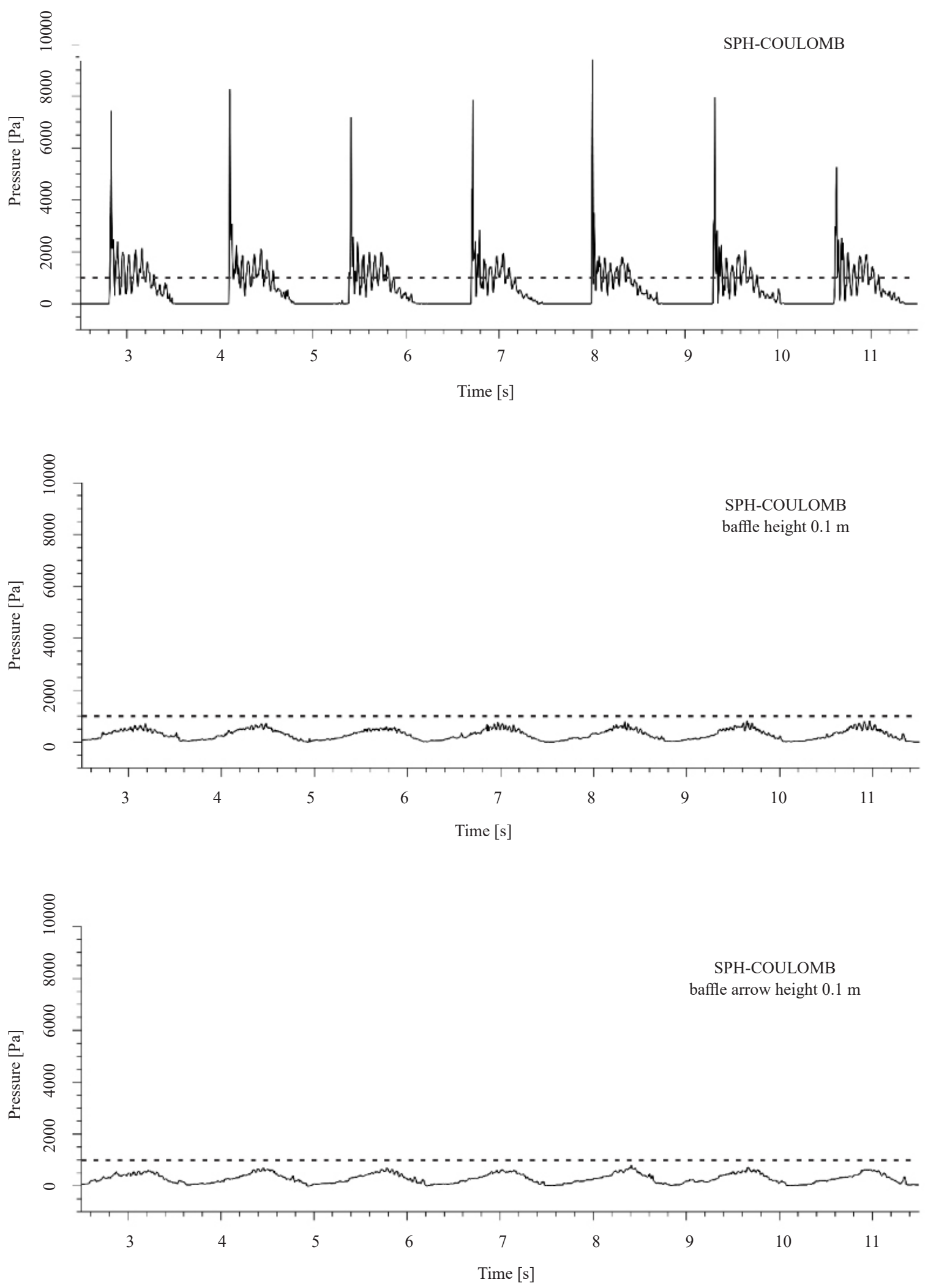

Figure 16. Pressure versus Time for three different scenarios. The dashed line indicates the pressure of $1000 \mathrm{~Pa}$ 


\section{Conclusion}

In this study, the number of particles used during the contour treatment was 616. Using this configuration, the suppression mechanisms, under the same flow conditions, were tested. It has been found that inadequate baffles height may lead to undesirable effects. Two heights were tested, in which the baffles with a height equal to 0.1 meters showed a good reduction in the hydrodynamic load on the walls.

In another scenario, the attenuation device took the form of an arrow. Both qualitatively and quantitatively, among all the baffles used, it proved to be more efficient as a suppression tool. The dashed lines in $1000 \mathrm{~Pa}$ in Figure 13 were placed to visualize the variation between the highest points of pressure better. In this way, we conclude that for the level of the adopted filling, the baffles with the last configuration lead to a greater reduction of the effects produced by sloshing.

We agree with Tsukamoto [11] when he states that deflectors are useless at high levels of filling. The baffles caused destructive interference in a dynamic behavior only at suitable heights.

In all cases, non-physical fluctuations of pressure appeared and edge effects were observed. Even with these numerical diffusions, our model behaved effectively, reproducing with excellent approximations the qualitative and quantitative data, in this way, we can affirm that the underestimates did not cause damages to the results, with acceptable approximations when compared to their respective experiments. In addition, the arrow-shaped baffles presented a small improvement compared to the vertical deflectors for the same height, which is a strong indication that a more detailed study on the baffles morphology could generate a more significant reduction of the hydrodynamic loads on the walls.

\section{Responsibility notice}

The author(s) is (are) the only responsible for the printed material included in this paper. Fora BOLSONARO.

\section{Acknowledgments}

National Agency for Petroleum, Natural Gas and Biofuels, Institutional Program of the Federal University of Espírito Santo in Oil and Gas (PRH-29-ANP) and Foundation for Support to Research and Innovation of Espírito Santo.

\section{Conflict of interest}

The authors declare no conflict of interest.

\section{References}

[1] S. D. Poisson, "On the small oscillations of the water contained in a cylinder," Annales de Mathématiques Pures et Appliquées, vol. XIX, pp. 225, 1828-1829.

[2] J. W. S. Rayleigh, “On the resistance of fluids, Phil. Mag," Scientific Papers 1, vol. 5, no. 2, pp. 430-441, 1876.

[3] H. Lamb, Hydrodynamics. Cambridge University Press, 1932, pp. 371.

[4] A. T. Chwang, "Effect of hydrodynamic interaction on the motion of a rotating body," Journal of the Brazilian Society of Mechanical Sciences and Engineering, vol. XXVI, no. 4, pp. 349, 2004.

[5] NASA, "Slosh supression," Space Vehicle Design Criteria (estructures), NASA SP-8031, pp. 36, 1969. Available: http://www.zerognews.com/special/sp8000/archive/ 00000024/01/sp8031.pdf [Accessed February 22, 2017].

[6] W. Graham, "The Forces Produced by Fuel Oscillation in a Rectangular Tank," Douglas Aircraft Company Inc., California, USA, Report. SM-13748, 1951.

[7] O. R. Filho, "Estudo da influência do nível de alagamento sobre a estabilidade dinâmica de pesqueiros (in Portuguese)," Master's degree thesis (Naval and Oceanic engineering), Escola Politécnica, Universidade de São Paulo. 2006. Available: http://www.teses.usp.br/teses/disponiveis/3/3135/tde-19092006-165959/pt-br.php 
[Accessed February 22, 2017].

[8] R. A. Ibrahim, Liquid Sloshing Dynamics: Theory and Applications. Cambridge University Press, 2005.

[9] D. P. Carneiro Junior, "Comportamento de líquidos no espaço-sloshing e amortecedores de nutação viscosos (in Portuguese)," Dissertação (Mestrado em Mecânica Espacial e Controle)-Instituto Nacional de Pesquisas Espaciais, São José dos Campos, 2009.

[10] M. M. Tsukamoto, "Modelagem Analítica e Simulação Numérica de um Sistema de Supressão de Sloshing (in Portuguese)," Doctor's degree thesis (Naval and Oceanic engineering), Escola Politécnica, Universidade de São Paulo, 2010. Available: http://www.teses.usp.br/teses/disponiveis/3/3135/tde-26082011-142211/pt-br.php [Accessed February 22, 2017].

[11] B. Thirunavukkarasu, and T. K. R. Rajagopal, "Numerical investigation of sloshing in tank with horivert baffles under resonant excitation using CFD code," Thin-Walled Structures, Vol. 161, 107517, 2021. Available: doi: 10.1016/j.tws.2021.107517.

[12] L. B. Lucy, "A numerical approach to the testing of the fission hypothesis," The Astronomical Journal, vol. 82, no. 12, pp. 1013-1024, 1977.

[13] R. A. Gingold, and J. J. Monaghan, "Smoothed particle hydrodynamics: theory and application to non-spherical stars," Monthly Notices of the Royal Astronomic Society, vol. 181, no. 3, pp. 375-389, 1977.

[14] G. R. Liu, and M. R. Liu, Smooth Particle Hydrodynamics: A Meshfree Particle Method. Singapore: World Scientific Publishing Company, 2003.

[15] Z. R. Kishev, C. Hu, and M. Kashiwagi, "Numerical simulation of violent sloshing by a CIP-based method," Journal of Marine Science and Technology, vol. 11, no. 2, pp. 111-122, 2006.

[16] H. Gotoh, A. Khayyer, A. H. Ikari, T. Arikawa, and K. Shimosako, "On enhancement of Incompressible SPH method for simulation of violent sloshing flows," Applied Ocean Research, vol. 46, pp. 104-115, 2014.

[17] D. A. Barbosa, and F. P. Piccoli, "Comparing the force due to the Lennard-Jones potential and the Coulomb force in the SPH Method," Journal of Ocean Engineering and Science, vol. 3, no. 4, pp. 310-315, 2018.

[18] D. A. Barbosa, and F. P. Piccoli, "Redução da Carga Hidrodinâmica em Tanques Por Adição de Defletores (in Portuguese),” In: Anais do XIII SIMMEC 2018-Simpósio de Mecânica Computacional, 2018. Available: https:// www.doity.com.br/anais/xiiisimmec2018/trabalho/65765 [Accessed December 19, 2019]. 